\title{
Identificación por PCR de Brucella canis en sangre y leche canina. Reporte de un caso
}

\author{
PCR identification of Brucella canis in canine blood and milk. A case report
}

\author{
M Olivera $^{\mathrm{a}^{*}}$, CA Giraldo ${ }^{\mathrm{b}}$, C Di-Lorenzo ${ }^{\mathrm{c}}$ \\ ${ }^{\mathrm{a}, \mathrm{b}}$ Grupo Vericel, Grupo Biogénesis, Facultad de Ciencias Agrarias, Universidad de Antioquia, Medellín, Colombia. \\ ${ }^{\text {c }}$ Laboratorio de Inmunología, Facultad de Ciencias Veterinarias, Universidad Nacional de La Plata, La Plata, Argentina.
}

\begin{abstract}
SUMMARY
Canine brucellosis is a disease caused by Brucella canis that is associated to reproductive problems in dogs, and it is also known as zoonosis. These bacteria are excreted in urine, milk, fetus or semen of infected animals, and the transmission occurs via sexual, oral, nasal or conjunctival contact. Diagnosis is usually done through serology but confirmation requires isolation of bacterial culture, a costly process that requires laboratory biosafety level 3. Molecular techniques are a valid method to determine the bacterial DNA, offering high specificity and sensitivity. This study reports the evaluation of a PCR test usually applied to isolates, as a test for clinical use. A healthy female canine with a history of previous brucellosis, feeding her 4-day old healthy newborns, was submitted to a rapid serologic test with $2 \beta$-mercaptoethanol, haemoculture and PCR, of milk and blood. All the tests resulted positive to Brucella canis. This is the first report of a positive result to B. canis by PCR and it confirms that clinically healthy individuals shed the bacterium through milk, representing a risk of infection for neonates and humans.
\end{abstract}

Palabras clave: zoonosis, neonatos, asintomático, cronicidad.

Key words: zoonosis, neonates, asymptomatic, chronicity.

\section{INTRODUCCIÓN}

La Brucella canis (B. canis), aislada por primera vez en 1967 (Carmichael y Kenney 1968), es la principal bacteria causante de enfermedades reproductivas en los caninos. Epidemiológicamente se distribuye a nivel mundial (Myers y Varela-Díaz 1980, Wanke 2004). En Colombia se aisló por primera vez de sangre en 2005, con un reporte de casos positivos del 17,2\% (Jara y col 2005), y desde entonces los reportes muestran frecuencias de positividad sérica entre un 1,4 a un $11 \%$ en mascotas, criaderos y albergues (Giraldo y col 2009, Ruiz y col 2010, Pardo y col 2009).

La transmisión de la enfermedad se da por vía sexual, oral, nasal o conjuntival, por la eliminación de la bacteria en la orina (Serikawa y col 1981), leche (Di-Lorenzo y Olivera 2008), fetos o semen de los animales enfermos, placenta y líquidos placentarios contaminados (BoriePolanco 2005, Keid y col 2007a). Cuando la enfermedad se vuelve crónica, es común encontrar pacientes asintomáticos seropositivos o con bacteremia (Hollet 2006).

En el diagnóstico de rutina se usa la prueba serológica de aglutinación rápida en placa $2 \beta$-mercaptoetanol (PRAP2ME), que detecta anticuerpos específicos (Badakhsh y col 1982), con el problema de que hay una proporción significativa de resultados falsos negativos (Keid y col 2009). La confirmación del diagnóstico serológico se realiza por medio del aislamiento de la bacteria. Esta

Aceptado: 19.01.2011.

* Facultad de Ciencias Agrarias, Ciudadela de Robledo Carrera 75 No 65.87, A.A. 1226, Medellín, Colombia; syngamia@gmail.com prueba requiere un periodo prolongado de tiempo hasta la identificación del agente y laboratorios de bioseguridad de nivel 3 (Lara y col 2007, Bounaadja y col 2009), lo que limita su implementación.

Los métodos de amplificación del ADN como la reacción en cadena de la polimerasa (PCR) han demostrado ser confirmatorios en el diagnóstico de brucelosis (Bricker 2002, Keid y col 2009), permiten acortar el tiempo de diagnóstico, reducir los riesgos de exposición y simplificar los requisitos de infraestructura necesarios.

Este trabajo presenta resultados de la utilización de la PCR para el diagnóstico clínico de brucelosis a partir de sangre total y leche en una perra recién parida, con historia previa de brucelosis.

\section{MATERIAL Y MÉTODOS}

\section{ANAMNESIS}

Hembra canina de 24 meses de edad, perteneciente a un criadero de 64 caninos donde 14 meses antes se había diagnosticado brucelosis canina con una seroprevalencia del 14\%. Las recomendaciones que se hicieron al propietario para controlar la enfermedad no fueron tenidas en cuenta (sacrificio de seropositivos, seguimiento serológico, cuarentena).

La perra se encontraba de una semana posparto, asintomática y amamantando cuatro cachorros aparentemente sanos. Su historia demostró que ya se le había aislado previamente B. canis (\# N $10135-5$ Dirección de Brucelosis de la Administración Nacional de Laboratorios e Institutos 
de Salud “Dr. Carlos Malbrán”, Rep. Argentina), además de haber sido positiva a las pruebas de PRAP-2ME, Inmunofluorescencia indirecta y ELISA Indirecta.

\section{PRUEBAS DE LABORATORIO}

Muestras. Se tomaron muestras de sangre en tubo seco, sangre en caldo infusión cerebro-corazón con citrato de sodio, sangre en tubo con EDTA y leche. Se le realizaron PRAP-2ME, hemocultivo y PCR a las muestras de sangre total y leche entera.

Examen serológico PRAP-2ME. Se mezclaron $25 \mu \mathrm{ldel}$ suero, $25 \mu \mathrm{l}$ de $2 \beta$-mercaptoetanol y $50 \mu \mathrm{l}$ de antígeno (B. canis $\mathrm{M}-$ ). Se espera dos minutos y se reportan como positivos si se presentan pequeñas aglutinaciones visibles a contraluz (Carmichael y Joubert 1987).

Hemocultivo y aislamiento. Se realizó un hemocultivo a partir de la sangre de la paciente, en medio caldo cerebrocorazón con citrato de sodio, durante 48 horas a $37^{\circ} \mathrm{C}$, con repiques ciegos en agar tripticasa soya, durante 24 horas a $37^{\circ} \mathrm{C}$.

La muestra de leche fue sembrada directamente en agar y se incubó de la misma forma.

La identificación de los microorganismos obtenidos a partir del crecimiento de colonias pequeñas se realizó por las pruebas bioquímicas y morfológicas rutinarias para B. canis y se certificaron en el Instituto Carlos Malbrán.

\section{DIAGNÓSTICO POR PCR}

Se extrajo ADN de las muestras de sangre total, leche, hemocultivo y de la cepa aislada, utilizando el kit comercial Genomic DNA Purification Kit (Fermentas). Para la cuantificación de ADN se usó un kit comercial (QuantiT $^{\mathrm{TM}}$ dsDNA HS Assay Kit, Lot 55810 , Invitrogen) y se leyó en un flurómetro (Fluorometer Qubit, Invitrogen). Para los cebadores y la PCR se usó el método descrito por García-Yoldi y col (2006) (cuadro 1). Como controles de especificidad de cebadores se usaron suspensiones de cepas de B. abortus cepa 19 y B. abortus cepa RB51; como control de la cepa de $B$. canis se usó la cepa de referencia usada por García-Yoldi RM6/66 (ATCC23365); como control interno se utilizó el gen constitutivo GAPDH; como control negativo se usaron todos los reactivos de PCR sin DNA.

Para la PCR se utilizó 1 ul de ADN en un volumen final de 25 ul que contenía: buffer KCL $1 X \sin \mathrm{MgCl} 2$, $3 \mathrm{mM}$ de $\mathrm{NgCl} 2$, 400uM de dNTP (Promega corp®), 1,5 U de taq DNA polimerasa (Invitrogen $®$ ) y 6,25 pmol de cada primer. La amplificación se realizó en un MJ Research Peltier Termal Cycler PTC 100 en un total de 25 ciclos. Cada ciclo consistía en una temperatura de desnaturalización de $95^{\circ} \mathrm{C}$ por 1 minuto, alineamiento de los primers a $64{ }^{\circ} \mathrm{C}$ por 45 segundos; la extensión de los primers se realizó a $72{ }^{\circ} \mathrm{C}$ por tres minutos. Después de los 25 ciclos se realizó una extensión final de $72{ }^{\circ} \mathrm{C}$ por seis minutos. Los productos de la PCR fueron visualizados en

Cuadro 1. Primers usados para la PCR de este estudio. ${ }^{a} L o s$ números BMEI o BMEII designan el loci para el genoma de B. melitensis,

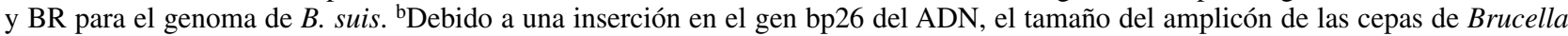
aisladas de mamíferos acuáticos es de 1.320 bp. f, forward; r, reverse.

PCR primers used in this study. ${ }^{a} \mathrm{BMEI}$ or BMEII numbers designate loci in B. melitensis genome, and BR in B. suis genome. f, forward; $\mathrm{r}$, reverse. ${ }^{b}$ Due an DNA insertion in the bp26 gene, the amplicon size in Brucella strains isolated from marine mammals is 1,320 bp. f, forward; $\mathrm{r}$, reverse.

\begin{tabular}{lcc}
\hline Primer $^{\mathrm{a}}$ & Secuencia $\left(5^{\prime}-3^{\prime}\right)$ & Tamaño amplicón (bp) \\
\hline BMEI0998f & ATC CTA TTG CCC CGA TAA GG & 1.682 \\
BMEI0997r & GCT TCG CAT TTT CAC TGT AGC \\
BMEI0535f & GCG CAT TCT TCG GTT ATG AA & $450(1.320)^{\mathrm{b}}$ \\
BMEI0536r & CGC AGG CGA AAA CAG CTA TAA & 794 \\
BMEI1436f & ACG CAG ACG ACC TTC GGT AT & 587 \\
BMEI1435r & TTT ATC CAT CGC CCT GTC AC & \\
BMEII0428f & GCC GCT ATT ATG TGG ACT GG & 272 \\
BMEII0428r & AAT GAC TTC ACG GTC GTT CG \\
BR0953f & GGA ACA CTA CGC CAC CTT GT & 218 \\
BR0953r & GAT GGA GCA AAC GCT GAA G & 152 \\
BMEI0752f & CAG GCA AAC CCT CAG AAG C & \\
BMEI0752r & GAT GTG GTA ACG CAC ACC AA & \\
BMEII0987f & CGC AGA CAG TGA CCA TCA AA & \\
BMEII0987r & GTA TTC AGC CCC CGT TAC CT & \\
\hline
\end{tabular}




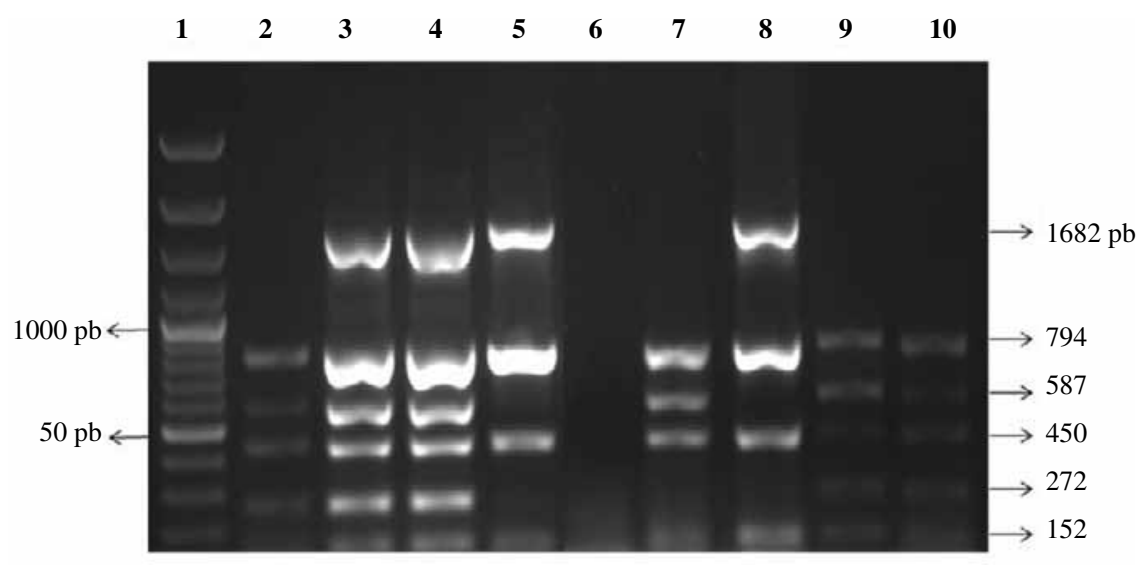

Figura 1. Electroforesis en gel de agarosa al 1,5\% teñido con bromuro de etidio. Línea 1, Marcador de peso molecular 100 pb (Fermentas); línea 2, B. canis Rm6/66 1; línea 3, control negativo; línea 4, B. abortus RB51; línea 5, B. abortus S19; línea 6, B. canis directamente de muestra de sangre total; línea 7, B. canis directamente de muestra de leche.

Agarose gel electrophoresis stained with $1.5 \%$ ethidium bromide. Line 1, molecular weight marker 100 bp (Fermentas); line 2, B. canis Rm6/66 1; line 3, negative control; line 4, B. abortus RB51; line 5, B. abortus S19; line 6, B. canis directly from whole blood sample; line 7: B. canis directly from milk sample.

una electroforesis en gel de agarosa al 1,5\%, teñido con bromuro de etidio y evaluado bajo luz UV. Se utilizó un marcador de peso molecular de $100 \mathrm{pb}$ (Fermentas Gene Ruler 100 bp DNA Ladder 0,5 ug/ul).

\section{RESULTADOS Y DISCUSIÓN}

La prueba sérica fue positiva, el hemocultivo (sangre \#11907-1, leche \#11907-12) y la PCR resultaron positivos para la sangre y para la leche, lo que indica que la perra continuó infectada crónicamente.

En cuanto a la PCR, a partir de sangre total y leche se observó el mismo patrón que reportaron García-Yoldi y col (2006): 4 bandas (152, 272, 450, 587 pb) correspondientes a $B$. canis; además mostró la 794 pb, que está reportada para $B$. suis, pero que García-Yoldi en comunicación personal con los autores confirma que hay cepas de campo que la presentan; la banda de 1682 de $B$. canis no se observó, debido posiblemente a la cantidad de DNA que puede extraerse de una muestra clínica. Las cepas B. abortus RB51 4 bandas $(152,450,580$ y 794 bp) y S19 4 bandas (152, 450, 794 y 1682 bp) fueron utilizadas como controles de especificidad (figura 1).

La prueba de PCR diseñada por García-Yoldi y col (2006) se corrió sobre extracciones de ADN a partir de cultivos bacteriales de las cepas de referencia; sin embargo, al probar la técnica en una muestra clínica de sangre y leche de un animal crónicamente infectado bacterémico y asintomático se determina que tiene muy buen valor diagnóstico. Keid y col $\left(2007^{\mathrm{b}}\right)$ ya habían demostrado que la prueba de PCR usando el 16S-23S rADN interspacer tiene una sensibilidad y especificidad diagnóstica del $100 \%$, con una capacidad de detección de 3.8 fg de ADN de $B$. canis que representa una concentración bacterial de al menos dos bacterias.
Por primera vez se demuestra que la técnica de PCR sirve para el diagnóstico directamente de la leche, lo que aumenta los usos de la prueba. Algunos investigadores la habían aplicado para el diagnóstico clínico a partir de sangre, hisopados vaginales y semen (Keid y col 2007 ), mientras que otros la usaron para el diagnóstico a partir de muestras de ganglios linfáticos (Aras y Uçan 2010). Los autores concuerdan en que el diagnóstico molecular por PCR es una herramienta útil, especialmente porque hay un grupo significativo de animales infectados, que aparecen negativos en las pruebas serológicas. Además puede convertirse en un protocolo de laboratorio que no es peligroso para el personal y puede ser realizado en un día (Aras y Uçan 2010).

Se corrobora con este caso que un animal con historia de infección por $B$. canis puede dar a luz camadas vivas y a término con o sin tratamiento de la enfermedad (Hollett 2006, Wanke y col 2006); es importante anotar que la leche es una vía de eliminación de la bacteria, lo que sería una posible vía de infección a los neonatos, aunque aún no se ha demostrado. Los resultados del trabajo confirman el riesgo de transmisión tanto horizontal (la leche) como vertical (aislamiento bacteriológico en la madre) que un animal positivo puede representar en un criadero, no sólo para los demás animales convivientes sino también para los humanos en contacto con las secreciones (Olivera y Di-Lorenzo 2009), por ser una zoonosis.

Con respecto a la clasificación de la evolución de la enfermedad, aunque Keid y col (2009) clasifican un hallazgo positivo al aislamiento y positivo a PCR como determinante de una fase aguda de la infección, el reporte de este caso no concuerda, ya que el animal estaba crónicamente infectado, no presentaba ningún signo clínico de la enfermedad y había parido cachorros. Es decir, que la enfermedad puede cursar como crónica, asintomática pero bactéremica y con eliminación por fluidos como la leche. 


\section{RESUMEN}

La brucelosis canina, producida por Brucella canis, es una enfermedad asociada a problemas reproductivos y de carácter zoonótico. Estas bacterias son excretadas en orina, leche, fetos o semen de los animales infectados y la transmisión ocurre por contacto vía sexual, oral, nasal o conjuntival. El diagnóstico de rutina se realiza por serología, pero la confirmación requiere aislamiento del cultivo bacterial, lo cual es costoso y requiere laboratorios con nivel 3 de bioseguridad. Las técnicas moleculares son una posibilidad reconocida para determinar el ADN bacterial, con alta especificidad y sensibilidad. Este reporte evaluó como prueba de aplicación clínica una técnica de PCR desarrollada para cultivos bacteriales. A una hembra canina asintomática, con historia previa de la enfermedad, amamantando una camada sana de 4 días de nacidos, se le realizó la prueba serológica rápida en placa con $2 \beta$-mercaptoetanol, hemocultivo y PCR, de leche y de sangre. Todas las pruebas fueron positivas a Brucella canis. Este es el primer reporte de diagnóstico en leche por PCR, lo que corrobora que animales clínicamente asintomáticos eliminan la bacteria por esta vía, lo que constituye un riesgo de infección para los neonatos y el riesgo zoonótico para veterinarios, propietarios del animal o personas que intervengan en el parto si no se toman medidas higiénicas preventivas.

\section{AGRADECIMIENTOS}

Los autores agradecen a Miriam Sánchez por su contribución a la discusión del artículo, al profesor Carlos Muskus y a María Teresa Guerra por la ayuda en el laboratorio molecular.

\section{REFERENCIAS}

Aras Z, U Uçan. 2010. Detection of Brucella canis from inguinal lymph nodes of naturally infected dogs by PCR. Theriogenology 74, 658-662.

Badakhsh FF, LE Carmichael, JA Douglass. 1982. Improved rapid slide agglutination test for presumptive diagnosis of canine brucelosis. J Clin Microbiol 15, 286-289.

Borie-Polanco C. 2005. Infertilidad canina por Brucella canis. En: Olivera M, Gobelo C (eds). El Libro Latinoamericano de Reproducción Canina y Felina. Ed. Biogénesis, Medellín, Colombia, Pp 249-265.

Bounaadja L, D Albert, B Chénais, S Hénault, MS Zygmunt, S Poliak, B Garin-Bastuji. 2009. Real-time PCR for identification of Brucella spp.: a comparative study of IS711, bcsp31 and per target genes. Vet Microbiol 28, 156-64.

Bricker BJ. 2002. PCR as a diagnostic tool for brucellosis. Vet Microbiol 90, 435-446.

Carmichael LE, RM Kenney. 1968. Canine abortion caused by Brucella canis. J Am Vet Med Assoc 152, 605-616.

Carmichael LE, JC Joubert. 1987. A rapid slide agglutination test for the serodiagnosis of Brucella canis infection that employs a variant (M-) organism as antigen. Cornell Vet 77, 3.
Di-Lorenzo C, M Olivera. 2008. Aislamiento de Brucella canis de leche de hembra canina infectada crónicamente. Memorias del XXI Congreso Panamericano de Ciencias Veterinarias (PANVET), 12-16 de octubre de 2008, Guadalajara, México.

García-Yoldi D, CM Marín, MJ de Miguel, PM Muñoz, JL Vizmanos, I López-Goñi. 2006. Multiplex PCR Assay for the identification and differentiation of all Brucella Species and the vaccine strains Brucella abortus S19 and RB51 and Brucella melitensis. Clin Chem 52, 779-781.

Giraldo CA, ZT Ruiz-Cortés, M Olivera. 2009. Brucella canis en Medellín (Colombia), un problema actual. Rev UDCA Act \& Div Cient 12, 210-220.

Hollett R B. 2006. Canine brucellosis: Outbreaks and compliance. Theriogenology 66, 575-587.

Jara S, O Pérez, C Di-Lorenzo, M Olivera. 2005. Diagnóstico de brucelosis canina mediante aglutinación en placa en caninos de Medellín, Colombia. Rev Col Cienc Pec 18, 4.

Keid LB, RM Soares, SA Vasconcellos, J Megid, VR Salgado, LJ Richtzenhain. 2009. Comparison of agar gel immunodiffusion test, rapid slide agglutination test, microbiological culture and PCR for the diagnosis of canine brucellosis. Res Vet Sci 86, 22-26.

Keid LB, RM Soares, SA Vasconcellos, DP Chiebao, VR Salgado, J Megid, LJ Richtzenhain. 2007 . A polymerase chain reaction for detection of Brucella canis in vaginal swabs of naturally infected bitches. Theriogenology 68, 1260-1270.

Keid L, R Soares, NR Vieira, J Megid, VR Salgado, SA Vasconcellos, M da Costa, F Gregori, LJ Richtzenhain. 2007 ${ }^{\mathrm{b}}$. Diagnosis of canine brucellosis: comparison between serological and microbiological tests and a PCR based on primers to $16 \mathrm{~S}-23 \mathrm{~S}$ rDNA interspacer. Vet Res Commun 31, 951-965.

Lara HH, NV Ayala, C Rodríguez. 2007. Laboratorios de bioseguridad nivel 3 y 4: investigación de patógenos peligrosos. Rev Mex Patol Clin 54, 177-186.

Myers DM, VM Varela-Díaz. 1980. Serological and bacteriological detection of Brucella canis infection of stray dogs in Moreno, Argentina. Cornell Vet 70, 258-265.

Olivera M, C Di-Lorenzo. 2009. Aislamiento de Brucella canis de un humano conviviente con caninos infectados. Informe de un caso. Colomb Med 40, 218-220.

Pardo A, C Pérez, A Góngora, L Gómez, A Moreno. 2009. Encuesta exploratoria de infección por Brucella canis en perros de Villavicencio, Colombia. Rev. MVZ Córdoba 14, 1690-1696.

Ruiz JD, CA Giraldo, LV López, F Chica. 2010. Seroprevalencia de Brucella canis en perros callejeros del Centro de Bienestar Animal "La Perla", Medellín (Colombia). Rev Col Cienc Pec 23, 166-172.

Serikawa T, T Muraguchi, J Yamada, H Takada. 1981. Long-term observation of canine brucellosis: excretion of Brucella canis into urine of infected male dogs. Jikken Dobutsu 30, 7-14.

Wanke MM. 2004. Canine brucellosis. Anim Reprod Sci 82, 195-207.

Wanke M, M Delpino, PC Baldi. 2006. Use of enrofloxacin in the treatment of canine brucellosis in a dog kennel (clinical trial). Theriogenology 66, 1573-1578. 